professional playwright but by the participant physicists themselves, and one might have hoped that Segrè would have used the opportunity to offer a new twist to the relationship in question. Admittedly, there are quotations from the original Faust at the head of each chapter, as well as a chapter entitled 'Goethe and Faust' and another comparing the physicists' play with Goethe's original. But these instances are provided largely in isolation from the main narrative of the book.

In 1932, German was still the main language of physics - and culture - so the choice of Goethe's Faust as a basis for a satire enacted in German seems natural. Probably in anticipation of his likely readership, Segrè does not quote from the original German, but quotes instead from necessarily inferior English translations. The many quotations from Goethe's Faust are taken from Anna Swanwick's excellent, but by now somewhat archaic, translation from late in the nineteenth century. Likewise, Segrès treatment of the physicists' Faust is based on the spirited, but sometimes inaccu- rate, English translation published in 1966 in a highly personal account, Thirty Years That Shook Physics, by the physicist George Gamow (to whom Segrè dedicates his book).

The photographs used to illustrate Faust in Copenhagen are well chosen. Apart from a few minor omissions and factual errors, the book is lively and readable and provides an exciting impression of the development of theoretical physics during a crucial period.

Finn Aaserud is director of the Niels Bohr Archive, Blegdamsvej 17, DK-2100 Copenhagen, Denmark.

\title{
Medical history without frontiers
}

\section{Medieval Islamic Medicine \\ by Peter Pormann and Emilie Savage- Smith \\ Georgetown University Press/Edinburgh \\ University Press: 2007. 223/256 pp. \\ $\$ 29.95 / € 18.99$}

\section{Yasmin Khan}

What is 'Islamic medicine'? It is a term fraught with limitations. No definitive definition exists, but most reputable historians of medicine have characterized it by several key features. These include a chronological marker that spans a medieval period of a thousand years and encompasses specific but vast geographical regions from Spain and North Africa in the west, to central Asia and India in the east. Its successes were inspired implicitly by the Islamic faith, but sometimes involved discreet collaboration of Muslims with non-Muslims, who used Arabic as the lingua franca to cultivate the resulting phenomenon.

These idiosyncratic dynamics of Islamic medicine are explored in Medieval Islamic Medicine. With their meticulous research on newly translated manuscripts, two pre-eminent scholars of medical history, Pormann and Savage-Smith, have revisited the topic discussed in the classic text Islamic Medicine by Manfred Ullmann, published almost 30 years ago.

Their new, brief overview is destined to become a definitive entry-level textbook, owing in part to its simple structure, comprehensive analysis and succinct interpretation of key historical figures and their achievements. It relies on a thematic rather than chronological approach, which enhances its readability.

The book discusses the emergence of medieval Islamic medicine and the subsequent crosspollination with medicine in other cultures. We are given a sense of how Muslims perceived the body as well as the soul as precious, because it was derived from and accountable to God as the creator. The body therefore required constant and dutiful care, and had the right to be maintained and preserved and protected from abuse, meaning that the individual was bound to seek a cure for any ills. These sensibilities were influenced by precursor civilizations particularly ancient Greece - and reinforced by the Islamic faith.

Pormann and Savage-Smith refute the clichéd view that the Islamic medieval civilization was merely a bridge between ancient and modern medicine. They show how Muslims built on Greek knowledge, in addition to preserving and translating it. The resulting new ideas and theories later percolated further into the West through translation, trade and travel, as well as

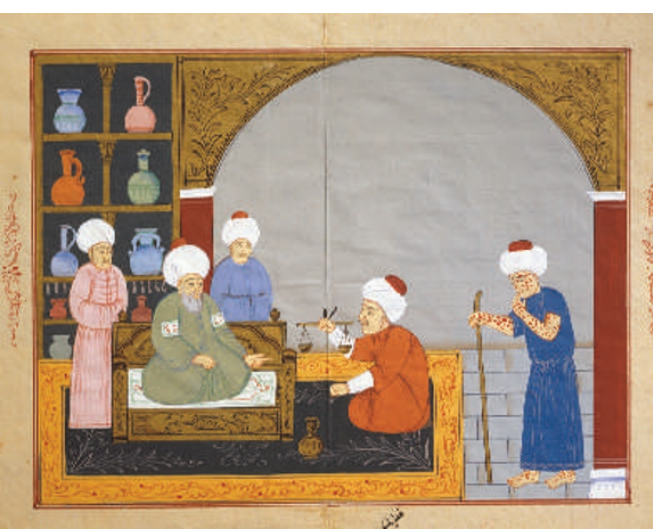

A Persian physician gives instructions for preparing smallpox remedies in the eleventh century.

during the crusades, acting as a springboard towards the European renaissance and thus forming the roots of modern medicine.

The book emphasizes the inclination of early Muslim medical practitioners towards Unani Tibb, a form of Islamic medical tradition stemming from early Greek medicine. This involved balancing, through diet and medicinal herbs, the four humours - air, earth, fire and water, which correspond to the four bodily fluids blood, phlegm, black bile and yellow bile - and understanding that a good environment and spiritual peace are essential for good health. Today such a holistic approach to well-being, although experiencing a resurgence, is outside mainstream modern medicine.

The authors avoid the irksome cumulative and linear approach that besets many texts and museum displays of medical history, which often portray the past as inferior and the present as the benchmark of progress. And without taking the 'great man of history' line, they give us Islamic medical pioneers aplenty - for example, Abu al-Qasim al-Zahrawi (Albucasis). This accomplished surgeon from eleventh-century Muslim Spain first described and used forceps for extracting fetuses during stillbirths, developed other specialized surgical tools, and sutured wounds using cat gut.

Pormann and Savage-Smith also discuss the role of women in the development of medieval Islamic healthcare. Patronage by wealthy women associated with those in power proved instrumental in providing the financial investment needed for establishing hospitals in Baghdad from the ninth century. These institutions offered free, specialized treatments, which resembled the founding ethos of the modern British National Health Service.

What led to the demise of the stronghold of Islamic medicine in general is not addressed in the book: this is an unresolved and complex question. Some blame religion, or the lack of it, and others point the finger at social factors such as war and colonialism. This subsidence has been perpetuated and exacerbated by the 'brain drain' phenomenon. That said, the legacy created by the practice of Islamic medicine is alive and thriving in the rural Middle East, throughout Africa, among the Muslims of southern Asia and in Asian diaspora communities in Europe and the United States, indicating that there is scope for a wider revival.

Medieval Islamic Medicine is a measured and scholarly book that is a timely rebuke to those tempted to dismiss the past as irrelevant. The medieval period when the Islamic world drove medical development and discovery is an indication that Islam itself is not inimical to progress. This book should be read by anyone interested in the real story of civilization. It is a notable contribution to the promotion of a multicultural public understanding of the history of science.

Yasmin Khan is exhibition coordinator at the Science Museum, Exhibition Road, London SW7 2DD, UK. 